\title{
A CASE OF BILATERAL FATIGUE FRACTURE OF THE FIBULA
}

BY

\author{
DAVID A. RICHMOND, B.Sc., F.R.C.S. \\ Orthopaedic Surgeon \\ AND
}

\section{J. SHAFAR, M.D., M.R.C.P., D.P.H. Physician}

\section{From the Burnley Group of Hospitals}

Fracture of a bone may result from ordinary functional activity in the absence of any obvious injury or violence. Such fractures are referred to as fatigue or stress fractures, and occur spontaneously in apparently normal bone as a consequence of the summation of stresses which singly are insufficient to produce fracture (Burrows, 1948). The incidence of this condition rose sharply during the second world war, but since then, as judged by published cases, it would appear to be an infrequent finding. By far the commonest site of this form of fracture is in one of the metatarsal bones ; the tibia is involved five or six times less frequently, and the fibula forty times less frequently (Hartley, 1943). The series of 32 fatigue fractures analysed by Richmond, 1945, showed the following locations : metatarsals, 25 ; upper third of tibia, 5, and lower third of fibula, 2 .

The case reported below is an example of fatigue fractures involving the lower third of both fibulae in a middle-aged housewife.

\section{Case History}

A married woman aged 45 was referred to one of us in a general medical clinic as a case of "arthritis of ankles." She complained of pain and swelling in both ankles. The pain had been noticed before the onset of the swelling, and had gradually become very severe-so much so that walking had become difficult. She lives in an upstairs flat and runs up and downstairs to and from a shop many times a day. The only unusual exercise undertaken recently has been that involved in using a treadle sewing-machine employing her right foot only. In addition she runs the flat for herself and her husband.

On examination there was a visible swelling $1 \frac{1}{2}$ in. $(3.8 \mathrm{~cm}$.) above the tip of the lateral malleolus on the right side. There was a tender bony thickening at this level on both sides. Pain could be elicited at these sites by everting or rotating the calcaneus in the ankle mortise. Similar pain was produced by fully dorsiflexing the foot at the anklejoint. Both heels showed eversion when standing. Radiographs showed fractures of both fibulae $1 \frac{1}{2}$ in. $(3.8 \mathrm{~cm}$.) above the malleolar tips, slightly oblique in direction as seen in the antero-posterior views. The lateral views showed little of the fractures. Callus was visible on both sides (see Figs.). No osteoporosis was evident in these films or in films of the hands.

Stirrup strapping was applied to both ankles and the patient was advised to curtail her activities as much as possible. Her signs and symptoms gradually improved, and four months later her pain had almost disappeared, and only slight bony thickening was apparent clinically.

\section{Comment}

The diagnosis of fatigue fracture rests on a consideration of the clinical features and radiological findings. Pain is the usual presenting symptom, and may be of acute onset or of gradually increasing severity. There is little in the patient's history to indicate the nature of the condition: since no record of injury or violence or of a sensation of snap is forthcoming, the possibility of fracture may well not arise.

The local signs are those of localized swelling and tenderness. Burrows (1948) has described three cases of fatigue fracture of the fibula in which tenderness was absent and five in which swelling was not evident. Oedema over the area of the dorsum of the foot may be present and local redness and increased temperature are other occasional findings. In unilateral examples limp does not appear to be a significant sign, but it was certainly a prominent feature in our case. Movement of the ankle-joint is unimpaired, but passive eversion of this articulation produces severe pain over the site of the fracture. Similar pain is produced by any movement which causes widening of the ankle mortise, such as full dorsiflexion of the foot.

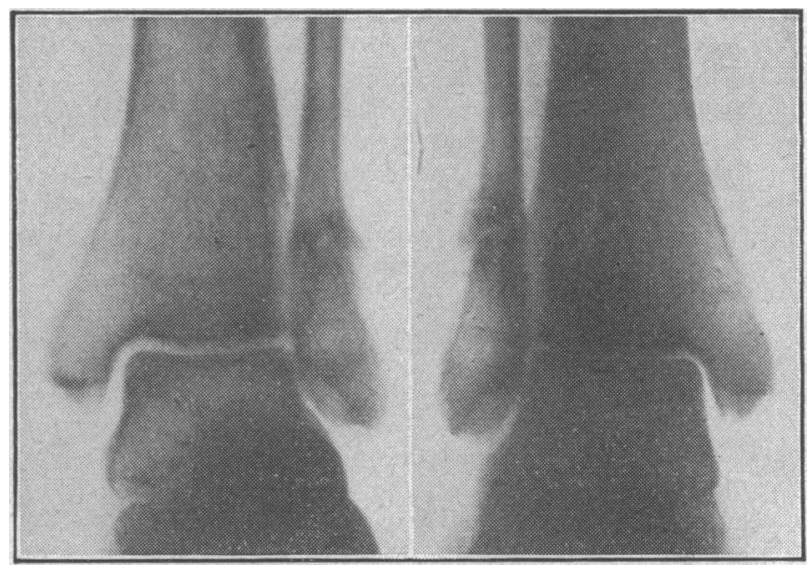

Radiograph showing fracture and callus formation of both fibulae.

Watson-Jones (1952) emphasizes that radiographs may show no abnormalities until the fissure is widened by reactionary osteoporosis, or until bone is laid down beneath the periosteum. Burrows states that a fracture line may be evident in some instances only at the end of the third week, and that even then it may be recognized only with the aid of a lens; a dense band is often the earliest change in the $x$-ray picture, and may be the last abnormality to clear. At a later date callus appears, and may consolidate and persist for many months as a bony buttress across the concavity or "stressed" aspect of the bone.

From his review of the literature and his own personal series of cases Burrows was able to segregate two groups in which fatigue fractures of the lowest third of the fibula occur. The first group comprises young athletes, such as runners and skaters. It is not difficult to understand the mechanism of production of the fracture or fractures in such activities. The second group, to which our own case belongs, is made up of women of middle age or over who are much on their feet in the course of the day. The aetiological factors in this second group are probably several. Burrows refutes the suggestion of Hartley (1943) that ostcoporosis plays any significant part in its causation.

The site of the fractures would seem to offer an explanation of the mode of production; in our case they were situated $1 \frac{1}{2}$ in. $(3.8 \mathrm{~cm}$.) above the tip of the lateral malleolus, and a similar level was noted by Burrows. Here the bone is largely cancellous in type and the fracture line is just below the interosseus ligament. Continued eversion of the feet, particularly in overweight females, will throw a strain on the lateral aspect of the fibula. The pull of the interosseous ligament medially and the forcing of the lower portion of the fibula in an outward direction will determine a focus of stress concentration at a point immediately below the ligament. It may well be, therefore, that at this focus deformation occurs which is at first elastic, and so reversible, but which later becomes permanent. As a copsequence of 
the localized molecular disruption there results a gradual spread towards the centre. The analogy to fatigue fractures in metals presents itself and would repay further study. It would be interesting to note whether the characters of the fractures in both types are similar. In those of metals the fracture is comparatively smooth at its outer zones where the surfaces have been rubbed together on innumerable occasions prior to the sudden spread of the fracture transversely, this suddenly fractured zone showing relative coarseness. Difficulty remains in affording an explanation for the predominance of this group of fatigue fractures of the fibula in females.

\section{Summary}

A case of bilateral fatigue fractures of the fibula in a middle-aged woman is reported.

Point tenderness, and pain at the same site when the ankle mortise was widened by everting the heels or dorsiflexing the foot, were features of the clinical findings.

The site of the fractures was identical with that described by Burrows (1948) in women of middle age.

Treatment advised was stirrup strapping and rest.

\section{REFERENCES}

Burrows, H. J. (1948). J. Bone Jt Surg., 30B, 266.

Hartley, J. B. (1943). Brit. J. Radiol., 16, 255.

Richmond, D A. (1945). Lancet, 1, 273.

Watson-Jones, Sir Reginald (1952). Fractures and Joint Injuries, 4th ed. Livingstone, Edinburgh.

\section{INTUSSUSCEPTION OF VERMIFORM APPENDIX IN ALLERGIC CHILDREN}

\author{
BY
}

R. G. MITCHELL, M.D., M.R.C.P.Ed., D.C.H.

Lecturer in Child Health, University of St. Andrews; lately Medical Registrar, the Royal Hospital for Sick Children, Edinburgh

Chronic intussusception is relatively rare in childhood and the symptoms are often ill defined, especially when the appendix is the site of intussusception. The following two cases are of interest because the presence of allergic disease caused difficulty in diagnosis. The age of the second patient makes her case additionally interesting, because this is only the second report of intussusception of the appendix in a child under $2 \frac{1}{2}$ years of age, the first being that of a boy aged 10 months (Forshall, 1953).

\section{Case 1}

A boy of 3 years was sent to the Royal Hospital for Sick Children because of attacks of diarrhoea with blood in the stools. A tentative diagnosis of gastro-intestinal allergy had been made because there was a history of infantile eczema.

After spontaneous delivery at term the child was breastfed for three weeks and then put on to cow's milk, following which he developed eczema. He had bronchitis at 6 months and measles at 1 year. There was no family history of allergic diseases. The patient was well until seventeen days before admission, when he passed a small quantity of bright red blood per rectum. Two days later he had a little diarrhoea and again passed blood. Treatment with a chalk mixture was prescribed and no further bleeding occurred for ten days. Five days before admission he passed several loose stools containing a larger amount of blood; he looked pale but not ill. On the day of admission he had an attack of abdominal pain and passed more blood in the stool.

Examination on admission showed a poorly nourished child with rough dry skin. A soft systolic murmur was heard at the apex of the heart, otherwise physical examination was negative. Blood examination revealed a moderate hypochromic anaemia.

On the day following admission he passed a dark stool, and a small, smooth, mobile mass was felt in the right iliac fossa which disappeared and reappeared at intervals during the next two days. $\mathrm{He}$ passed no further stools, but complained on one occasion of abdominal pain lasting for a few minutes. On the fourth day a tumour was felt extending from the right iliac fossa to the right hypochondrium, and at operation (Miss R. M. Mackay) a mass was found consisting of the caecum, into which the appendix had completely intussuscepted. There was no obvious impairment of the blood supply, but all layers were so oedematous that reduction was impossible. The caecum was opened, and the completely inverted and very swollen appendix was seen inside; the tip was just becoming gangrenous, but the rest was only congested. The appendix was removed and the caecum closed. Following blood transfusion, recovery was uneventful.

\section{Case 2}

A girl, aged 16 months at the first admission, was born spontaneously at term and was fed on dried milk. At the age of 6 weeks she developed infantile eczema, and at 6 months the introduction of egg into her diet resulted in vomiting and urticaria, which recurred whenever eggs were given. She had no other illnesses until 14 months, and there was no family history of allergy.

At 14 months she began to have attacks of abdominal pain and vomiting, lasting for a day or two at a time, and her appetite became poor. She passed normal stools between and during the attacks. On admission to Maryfield Hospital, Dundee, at 16 months of age, she was found to be a well-nourished child with extensive eczema, involving principally the shoulders, chest, and knees. No other abnormality was found and no mass was palpable in the abdomen. The haemoglobin was $11 \mathrm{~g} . \%$, the leucocyte count 12,000 per c.mm., and the erythrocyte sedimentation rate was $40 \mathrm{~mm}$. in the first hour (Westergren). The urine was normal. There was mucus and a little red blood in the stools, culture of which showed no pathogenic organisms. The Mantoux test was positive, but $x$-ray examination of the chest showed only increased broncho-vascular markings.

While in the ward she was inadvertently given an egg custard and had an immediate reaction consisting of generalized urticaria, vomiting, and abdominal pain, which promptly subsided on treatment with an antihistaminic drug.

A provisional diagnosis of gastro-intestinal allergy was made, but a barium enema examination was carried out to exclude any other condition in the bowel. There was a temporary hold-up of the barium in the ascending colon, but eventually normal filling was obtained. The possibility of an intussusception which had been reduced by the enema was considered, but as the symptoms had subsided she was allowed to go home.

She had no more trouble until two months later; when she was readmitted because of further attacks of abdominal discomfort followed by the passage of blood in the stools. Apart from extensive eczema, no abnormality was found on physical examination. A second barium enema showed good filling of the colon but defective filling of the caecum. Gastro-intestinal allergy was still thought to be the most likely cause of her symptoms, and as she was thriving she was discharged from hospital.

One month later she had three more attacks of abdominal colic with blood in the stools, and this time a horizontal thickening was palpable in the upper abdomen. At laparotomy (Mr. W. G. Campbell) a basal appendicular intussusception was found which had further intussuscepted into the colon. The intussusception was easily reduced except for the part formed by the base of the appendix, and the fundus of the caecum with the appendix was removed. Microscopical examination showed diffuse post-inflammatory fibrosis in the subserosa of the appendix, while the mucosa 